\title{
A European patient record study on diagnosis and treatment of chemotherapy-induced anaemia
}

\author{
Heinz Ludwig • M. Aapro • C. Bokemeyer • J. Glaspy • \\ M. Hedenus • T.J. Littlewood • A. Österborg • \\ B. Rzychon • D. Mitchell • Y. Beguin
}

Received: 23 January 2014 / Accepted: 2 March 2014 / Published online: 23 March 2014

(C) The Author(s) 2014. This article is published with open access at Springerlink.com

\begin{abstract}
Purpose Patients with cancer frequently experience chemotherapy-induced anaemia (CIA) and iron deficiency. Erythropoiesis-stimulating agents (ESAs), iron supplementation and blood transfusions are available therapies. This study evaluated routine practice in CIA management.

Methods Medical oncologists and/or haematologists from nine European countries $(n=375)$ were surveyed on their last five cancer patients treated for CIA $(n=1,730)$. Information was collected on tests performed at diagnosis of anaemia,
\end{abstract}

H. Ludwig $(\bowtie)$

Wilhelminen Cancer Research Institute, Wilhelminenspital,

Vienna, Austria

e-mail: heinz.ludwig@wienkav.at

\author{
M. Aapro \\ IMO Clinique de Genolier, Genolier, Switzerland \\ C. Bokemeyer \\ University of Hamburg, Hamburg, Germany \\ J. Glaspy \\ UCLA School of Medicine, Los Angeles, USA
}

M. Hedenus

Sundsvall Hospital, Sundsvall, Sweden

T. Littlewood

John Radcliffe Hospital, Oxford, UK

A. Österborg

Karolinska Institutet and Karolinska Hospital, Stockholm, Sweden

B. Rzychon • D. Mitchell

Vifor Pharma, Glattbrugg, Switzerland

Y. Beguin

CHU of Liège and University of Liège, Liège, Belgium levels of haemoglobin $(\mathrm{Hb})$, serum ferritin and transferrin saturation (TSAT), as well as applied anaemia therapies.

Results Diagnostic tests and therapies for CIA varied across Europe. Anaemia and iron status were mainly assessed by $\mathrm{Hb}$ (94\%) and ferritin (48\%) measurements. TSAT was only tested in $14 \%$. At anaemia diagnosis, $74 \%$ of patients had $\mathrm{Hb}$ $\leq 10 \mathrm{~g} / \mathrm{dL}$, including $15 \%$ with severe anaemia $(\mathrm{Hb}<8 \mathrm{~g} / \mathrm{dL})$. Low-iron levels (ferritin $\leq 100 \mathrm{ng} / \mathrm{mL}$ ) were detected in $42 \%$ of evaluated patients. ESA was used in $63 \%$ of patients, blood transfusions in $52 \%$ and iron supplementation in $31 \%$ (74 \% oral, $26 \%$ intravenous iron). Only $30 \%$ of ESA-treated patients received a combination of ESA and iron supplementation. Blood transfusions formed part of a regular anaemia treatment regimen in $76 \%$ of transfused patients. Management practices were similar in 2009 and 2011.

Conclusion Management of anaemia and iron status in patients treated for CIA varies substantially across Europe. Iron status is only assessed in half of the patients. In contrast to clinical evidence, iron treatment is underutilised and mainly based on oral iron supplementation. Implementation of guidelines needs to be increased to minimize the use of blood transfusions.

Keywords Anaemia Chemotherapy-induced anaemia Intravenous iron · Iron deficiency · Diagnosis ·

Erythropoiesis-stimulating agents

\section{Introduction}

Patients with cancer frequently experience chemotherapyinduced or cancer-related anaemia and iron deficiency (ID) $[1,2]$. Anaemia adds a substantial burden to these patients already affected by cancer and its treatment [1-3]. ID is a major component in the pathogenesis of anaemia in cancer patients [4] and has been estimated to affect 19-63\% of 
patients with different tumour types [5]. The prevalence of ID increases with progression of the disease and correlates with the prevalence of anaemia [2].

Impaired iron homeostasis (a common feature in chronic disease), chronic blood loss and nutritional deficiencies (e.g. cancer-induced anorexia) are the main causes of ID in cancer patients [5]. Early diagnosis and management of ID is important to reduce the risk of anaemia and improve patient care. Biological iron status markers include serum ferritin, which reflects storage iron under non-inflammatory conditions, and transferrin saturation (TSAT), reflecting circulating iron that is available for erythropoiesis. A low TSAT is related to both absolute and functional iron deficiency [6]. In absolute ID, iron stores are depleted (serum ferritin $\leq 100 \mathrm{ng} / \mathrm{mL}$ in patients with inflammation, including cancer) [5, 6]. Functional ID is characterised by a lack of available iron (TSAT $\leq 20 \%$ ) despite normal or elevated serum ferritin [5-7]. Most iron-deficient cancer patients present with functional ID [2].

Historically, anaemia in cancer patients was treated with red blood cell (RBC) transfusions or erythropoiesisstimulating agents (ESAs). However, a substantial proportion of anaemic cancer patients remain unresponsive to ESA treatment [8-10], and over recent years, evidence has accumulated that RBC transfusions, as well as ESA use outside the current label and guidelines, can increase all-cause mortality [11-13]. Current guidelines therefore recommend preventing RBC transfusions and using ESAs with the lowest effective dose and in approved indications only [14-20].

In ESA-treated patients with functional ID, concomitant administration of intravenous (i.v.) iron should be considered [14]. Several controlled clinical trials have shown that i.v. iron supplementation of ESA therapy enhances haematological response and may be effective in reducing ESA doses and transfusion requirements [21-26]. In contrast, administration of oral iron showed less or no effect in comparative trials [21, 25].

This cross-sectional study evaluated the routine practice in the diagnosis and treatment of anaemia and ID in patients with chemotherapy-induced anaemia (CIA) and the implementation of anaemia treatment guidelines into practical management.

\section{Materials and methods}

\section{Study populations}

Oncologist, haematologist and onco-haematologist (managing mainly solid or mainly haematological tumours), in the manuscript collectively referred to as medical oncologists and/ or haematologists, were selected at random from nine European countries. They reported data on their last five cancer patients treated for CIA within the preceding 6 months.
Patients who had not received any chemotherapy in the last 3 months and patients with myelodysplastic syndromes were excluded. Eligible medical oncologists and/or haematologists had to spend $>50 \%$ of their working time on patient care and personally see and treat more than five cancer patients with CIA per month.

Details on patients were collected from patient records in two surveys: from June to September 2009 in France (FR), Germany (DE), Spain (ES), Switzerland $(\mathrm{CH})$ and United Kingdom (UK) (survey 1) and from August to September 2010 in Austria (AT), Italy (IT), the Netherlands (NL) and Sweden (SE) (survey 2).

An additional data set was collected in survey 1 countries about 2 years after the first survey (June to August 2011). This data set was only used for comparison with the corresponding data set from 2009, to assess potential changes in routine practice over time. It was not included in the main analysis.

Data collected in patient record forms

Collected patient demographics included gender, age, weight, height, dietary habits, comorbidities, type and TNM stage of cancer. Data on anaemia management included a list of haematological tests performed at diagnosis of anaemia, levels of $\mathrm{Hb}$ and iron status parameters (serum ferritin, TSAT) and prescribed anaemia treatment. For all iron-treated patients, information on the iron administration route (oral, i.v., intramuscular) and the type of specialist that initiated the treatment were collected. Additional details, which were recorded during survey 1 only, included reasons for prescription of i.v. or oral iron as well as anaemia-related symptoms. In survey 2 , $\mathrm{RBC}$ transfusions were evaluated in more detail.

Some questions were stated in a slightly different way in survey 2 to avoid ambiguity that had been observed among responses to these questions in the first survey and to better reflect the time frames physicians referred to when asked for given treatments. The question for "current" anaemia treatment (survey 1) was extended to "current or last treatment" in survey 2 , and the question on whether a patient had "ever" received an RBC transfusion (survey 1) was limited to "during the last 12 months" in survey 2 .

Data collected in physician self-reporting section

In survey 1, participating medical oncologists and/or haematologists were asked to disclose the trigger points $(\mathrm{Hb}$ levels) they used for starting treatment in male/female patients and minimal target $\mathrm{Hb}$ levels.

Data analysis

Results are presented for all nine countries combined and as range of overall data in the individual countries (shown in 
square brackets). Alternatively, data from survey 1 or survey 2 countries only were combined, as indicated. Patients without current anaemia treatment (only in survey 1) were excluded from the analysis for better comparability of the results of the two surveys. Collected data were verified by plausibility checks and phone interviews of $10 \%$ of participants.

Due to the low number of patients receiving i.v. iron, information on the reasons for prescribing i.v. iron was gathered from an extended patient sample, for which each participating physician provided data from up to two additional i.v. iron-treated patients. The extended patient sample was not used in any of the other analyses.

\section{Results}

Baseline patient characteristics

In total, 375 medical oncologists and/or haematologists were recruited of whom 321 were hospital-based and 54 were, at least partially, office-based. Details on a total of 1,860 patients with CIA were collected. After excluding patients with no current anaemia treatment, 1,730 patients were included in the analysis (Table 1). Patients had a variety of haematological and solid malignancies and $46 \%$ had metastatic disease.

\section{Assessment of anaemia and iron status in cancer patients with CIA}

Diagnosis of anaemia was according to local definition and performed or confirmed by assessment of $\mathrm{Hb}$ levels in $94 \%$ [86-99\%] of the study population (Fig. 1a). The proportion of patients with $\mathrm{Hb}$ measurements was slightly higher in at least partially office-based vs. hospital-based medical oncologists and/or haematologists (96.7 vs. 93.5\%; $p=0.05$ ). Median $\mathrm{Hb}$ at diagnosis of anaemia was $9.1 \mathrm{~g} / \mathrm{dL}$ (range median levels across countries, [9.0-9.6 g/dL]; Table 1). Of the patients tested for $\mathrm{Hb}, 26 \%$ [14-40\%] presented with mild $(\mathrm{Hb}$ $\geq 10 \mathrm{~g} / \mathrm{dL}), 59 \%$ [49-68 \%] with moderate $(\mathrm{Hb} \leq 9.9$ and $\geq 8.0 \mathrm{~g} / \mathrm{dL})$ and $15 \%$ [9-24\%] with severe anaemia $(\mathrm{Hb}$ $<8 \mathrm{~g} / \mathrm{dL}$; Fig. 1b). Other tests performed were haematocrit (76\% [47-97\%]) and RBC indices.

Assessment of iron status was mainly based on serum ferritin measurements (48 \% [23-60\%]; Fig. 1a). The proportion of patients with serum ferritin assessment was significantly higher among office-based vs. entirely hospital-based medical oncologists and/or haematologists (60.8 vs. $45.3 \%$; $p=$ $0.001)$. Median ferritin at initial diagnosis was $150 \mathrm{ng} / \mathrm{mL}$ [50-243 ng/mL] (Table 1). Serum ferritin levels were low $(\leq 100 \mathrm{ng} / \mathrm{mL})$ in $42 \%$ [21-65\%] of tested patients, and $22 \%$ [8-41\%] even had ferritin $\leq 30 \mathrm{ng} / \mathrm{mL}$ (Fig. 1b). TSAT was only tested in a small percentage (14\% [2-25\%]; Fig. 1a). Median TSAT of tested patients was $29 \%$ [15-
$35 \%$ ] (Table 1 ), and over a quarter of tested patients $(27 \%$ [7-100\%]) had a TSAT $\leq 20 \%$, reflecting low amounts of circulating iron (Fig. 1b). The wide variation of TSAT values between the countries is probably due to the small number of tested patients. The rates of TSAT assessment were comparable for hospital-based and office-based medical oncologists and/or haematologists (16.3 vs. $13.3 \%$ ).

Treatment of anaemia and iron deficiency

ESA was the most common anaemia treatment in the evaluated population. It was used in $63 \%$ [15-100\%] of patients either alone or in combination with other anaemia treatments (Fig.2a). In $23 \%$ [9-46 \%], anaemia treatment included both ESAs and RBC transfusions. In total, RBC transfusions were administered to more than half of all patients (52\% [11$93 \%]$ ) at some stage (survey 1) or during the last 12 months (survey 2). RBC transfusions were more frequently administered by hospital-based than office-based medical oncologists and/or haematologists (53.9 vs. $43.3 \% ; p=0.005$ ). About a third of all patients (31\% [11-61\%]) received iron as current or last treatment. Overall, there was substantial variability across countries for all three treatment options.

Among iron-treated patients, the majority received an oral iron product (74\%) and only $26 \%$ [4-77\%] received i.v. iron (Fig.2b). Switzerland was the only country where the majority of iron-treated patients received i.v. iron (77\%). The proportion of patients receiving i.v. iron was higher among officebased than hospital-based medical oncologists and/or haematologists (15.9 vs. $7.5 \% ; p=0.001)$. A small percentage of iron-treated patients received iron supplementation as monotherapy without concomitant ESA or RBC transfusion (17\% oral and $5 \%$ i.v. iron). Of note, only $30 \%$ of ESAtreated patients received iron supplementation and among these, the majority $(70 \%)$ received oral iron.

\section{Use of iron therapy in survey 1 patients (FR, DE, ES, CH, UK)}

In survey 1 countries, further details on iron therapy were surveyed and analysed. On average, $67 \%$ of first prescriptions were for an oral iron formulation. In the UK, oral iron even accounted for all first prescriptions. Conversely, in Switzerland, $77 \%$ of first prescriptions were for an i.v. iron formulation. At commencement of iron therapy, mean $\mathrm{Hb}$, ferritin and TSAT levels were $9.2 \mathrm{~g} / \mathrm{dL}$ [8.6-9.3 g/dL], $120 \mathrm{ng} / \mathrm{mL}$ [59$187 \mathrm{ng} / \mathrm{mL}$ ] and $26 \%$ [15-32\%], respectively. A comparison of "current" vs. "previous" iron treatment revealed that the iron administration route was rarely switched in individual patients (overall only in $6 \%$ of iron-treated patients). Most commonly (in $56 \%$ of cases where there was a change), the switch was made from oral to i.v. iron.

Reasons for iron treatment selection were analysed in the extended patient sample. "Quick onset of action" was stated as 
Table. 1 Baseline patient characteristics and number of medical oncologists and/or haematologists by country

\begin{tabular}{|c|c|c|c|c|c|c|c|c|c|c|}
\hline & FR & $\mathrm{DE}$ & ES & $\mathrm{CH}$ & UK & AT & IT & NL & SE & Total $/$ mean \\
\hline $\begin{array}{l}\text { Medical oncologists and/or } \\
\text { haematologists }(n)\end{array}$ & 51 & 57 & 52 & 33 & 55 & 24 & 51 & 25 & 31 & 375 \\
\hline Patients $(n)$ & 237 & 262 & 228 & 135 & 217 & 119 & 254 & 124 & 154 & 1,730 \\
\hline \multicolumn{11}{|l|}{ Patient demographics } \\
\hline Male (\%) & 57 & 55 & 60 & 56 & 57 & 52 & 55 & 53 & 53 & 56 \\
\hline Age (years; mean) & 61 & 62 & 61 & 58 & 58 & 59 & 61 & 61 & 65 & 61 \\
\hline \multicolumn{11}{|c|}{ Type of cancer ( $\geq 10 \%$ each) and metastatic stage } \\
\hline Lymphoma (\%) & 27 & 18 & 26 & 24 & 17 & 13 & 21 & 10 & 26 & 21 \\
\hline Lung $(\%)$ & 10 & 21 & 15 & 13 & 7 & 14 & 18 & 13 & 1 & 13 \\
\hline Breast $(\%)$ & 12 & 15 & 9 & 10 & 10 & 19 & 17 & 18 & 9 & 13 \\
\hline Myeloma (\%) & 10 & 9 & 16 & 4 & 17 & 5 & 11 & 14 & 23 & 12 \\
\hline Colorectal (\%) & 8 & 11 & 7 & 6 & 10 & 16 & 11 & 8 & 11 & 10 \\
\hline Stage IV (\%) (any T, any N, M1) & 52 & 53 & 40 & 52 & 48 & 60 & 30 & 55 & 39 & 46 \\
\hline \multicolumn{11}{|l|}{$\mathrm{Hb}$ levels and iron status at diagnosis } \\
\hline \multicolumn{11}{|l|}{$\mathrm{Hb}(\mathrm{g} / \mathrm{dL})$} \\
\hline median & 9.0 & 9.1 & 9.5 & 9.6 & 9.0 & 9.0 & 9.0 & 9.4 & 9.2 & 9.1 \\
\hline range & $4.0-14.7$ & $6.1-14.7$ & $6.0-12.3$ & $2.8-13.3$ & $5.0-13.5$ & $4.0-12.5$ & $5.9-13.0$ & $7.0-12.0$ & $5.4-14.0$ & $2.8-14.7$ \\
\hline$(n)$ & $(231)$ & $(260)$ & $(202)$ & $(132)$ & $(214)$ & $(109)$ & (225) & (119) & (133) & $(1,625)$ \\
\hline \multicolumn{11}{|l|}{ Ferritin (ng/mL) } \\
\hline median & 215 & 237 & 127 & 150 & 100 & 243 & 50 & 65 & 99 & 150 \\
\hline range & $2-927$ & $2-999^{\mathrm{b}}$ & $5-999^{b}$ & $4-999^{b}$ & $4-632$ & $5-999^{\mathrm{b}}$ & $2-999^{b}$ & $5-452$ & $2-999^{\mathrm{b}}$ & $2-999^{\mathrm{b}}$ \\
\hline$(n)$ & (128) & $(158)$ & (137) & $(78)$ & $(80)$ & $(50)$ & $(124)$ & $(31)$ & $(35)$ & $(821)$ \\
\hline \multicolumn{11}{|l|}{$\operatorname{TSAT}(\%)^{\mathrm{a}}$} \\
\hline median & 30 & 28 & 26 & 18 & 22 & 15 & 35 & 15 & 30 & 29 \\
\hline range & $7-75$ & $5-70$ & $6-90$ & $16-20$ & $8-71$ & $2-45$ & $10-70$ & $12-16$ & $10-99$ & $2-99$ \\
\hline$(n)$ & (47) & $(25)$ & $(58)$ & (3) & $(25)$ & (17) & $(54)$ & (3) & (5) & (237) \\
\hline
\end{tabular}

FR France, DE Germany, ES Spain, CH Switzerland, UK United Kingdom, AT Austria, IT Italy, $N L$ the Netherlands, $S E$ Sweden, $H b$ haemoglobin, $T S A T$ transferrin saturation

${ }^{\text {a }}$ Small sample sizes due to low number of tested patients

${ }^{b} \geq 999 \mathrm{ng} / \mathrm{mL}$ (entry cut-off of the survey)

the main reason ( $37 \%)$ for selecting i.v. iron, whereas convenience rather than efficacy-related arguments were the main basis for using oral iron ("easy/convenient administration" (54\%), "familiarity" (46\%)). In $30 \%$ of cases, use of oral iron was justified by "effective when used in combination". Iron treatment was mainly initiated by medical oncologists and/or haematologists ( $98 \%$ of i.v. and $91 \%$ of oral iron treatments). In the UK, a notable minority of patients (17\%) received oral iron prescribed by general practitioners.

Mean self-reported $\mathrm{Hb}$ cut-off levels, at which surveyed medical oncologists and/or haematologists would initiate any kind of anaemia treatment, were $9.6 \mathrm{~g} / \mathrm{dL}[9.0-10.2 \mathrm{~g} / \mathrm{dL}]$ for male and $9.4 \mathrm{~g} / \mathrm{dL}[8.8-10.0 \mathrm{~g} / \mathrm{dL}]$ for female patients. Mean target $\mathrm{Hb}$ levels were $11.1 \mathrm{~g} / \mathrm{dL}$ [10.1-11.7 g/dL] and $10.9 \mathrm{~g} /$ $\mathrm{dL}[9.9-11.6 \mathrm{~g} / \mathrm{dL}]$ for male and female patients, respectively.

The most frequent anaemia signs and symptoms were fatigue, weakness, paleness and breathlessness, and there was a trend for a decrease in the proportion of symptomatic patients after iron treatment (fatigue, 71 to $64 \%$; weakness, 67 to $51 \%$; paleness, 51 to $36 \%$; breathlessness, 39 to $30 \%$ ). The proportion of patients being completely free of anaemia symptoms increased from 5 to $17 \%$.

\section{Use of RBC in survey 2 patients (AT, IT, NL, SE)}

Detailed questions regarding the use of RBC transfusions were asked during survey 2 . In the majority ( $76 \%$ ) of RBCtreated patients, transfusions formed part of a regular treatment regimen (vs. being an emergency administration due to a rapid drop in $\mathrm{Hb}$ ). In $45 \%$ [26-53\%] of RBC-treated patients, transfusions were given at a $\leq 3$-month interval and $3 \%$ received transfusions every week or even more frequently. Among the options in the questionnaire, "easily available" (47\% [15-68 \%]) and "uncomplicated procedure" (34\% [0$52 \%]$ ) were the most commonly selected reasons for administration of RBC transfusions. Further reasons were that the 
Fig. 1 a Diagnostic tests used to assess anaemia and iron status in cancer patients with CIA. $\mathrm{Hb}$ haemoglobin, TSAT transferrin saturation. b Proportion of anaemic cancer patients with low levels of haematological parameters at diagnosis of anaemia. $H b$ haemoglobin, TSAT transferrin saturation a

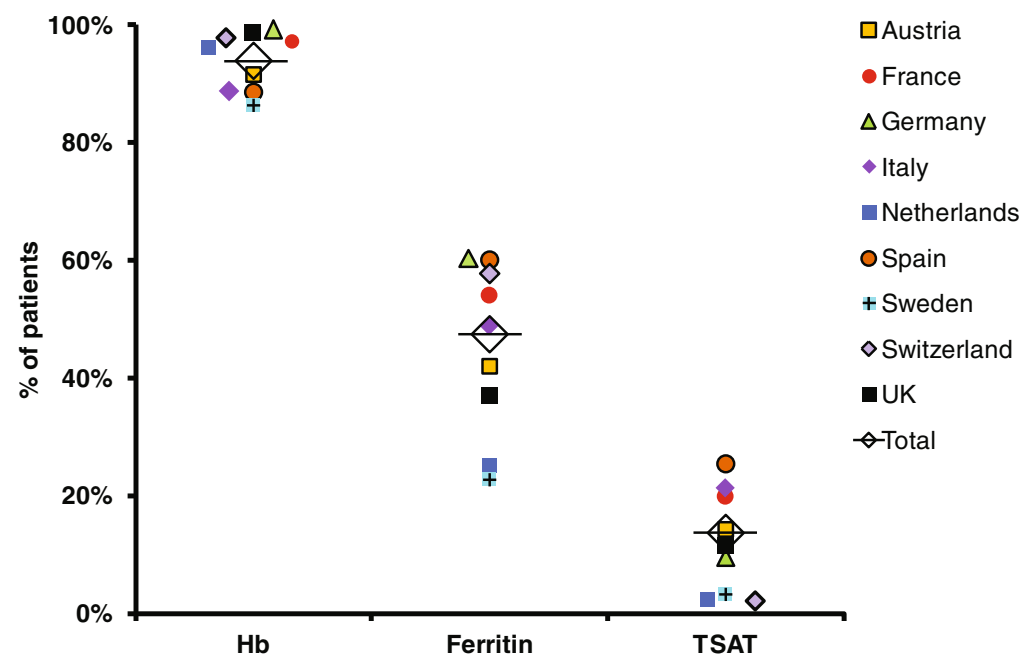

b

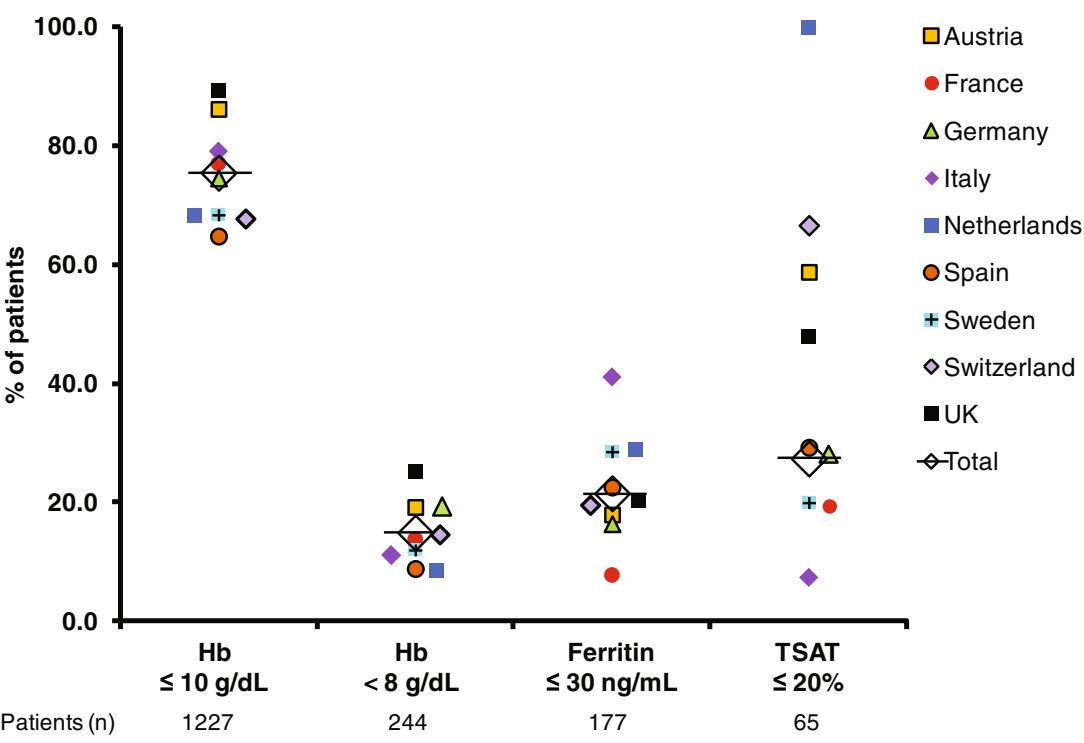

anaemia was not controlled by ESAs alone (29 \% [14-69 \%]) or by the given iron treatment (24\% [0-39\%]).

Potential changes in anaemia management from 2009 to 2011

Two years after the first study, the survey was repeated and 710 new cases of CIA were reported by 142 medical oncologists and/or haematologists. The patient population analysed in this follow-up survey was comparable to the one of the initial survey, with a similar gender and age distribution, and similar disease profile. The majority $(85 \%)$ of the surveyed medical oncologists and/or haematologists were hospitalbased and $15 \%$ were, at least partially, office-based.

As in the initial survey, anaemia and iron status were mainly assessed by measurement of $\mathrm{Hb}$ and serum ferritin (Table 2). Hb as a diagnostic test was slightly more frequently used in the second survey (98 vs. $89 \%$ ), while the frequency of serum ferritin tests was almost the same as in 2009 (49 vs. $48 \%$ ). A slight improvement was seen in the utilisation of TSAT, the use of which nearly doubled in 2011 (23\% [14$39 \%$ ] vs. $13 \%$ [4-23\%]) but still remained low compared to ferritin tests. Median values for $\mathrm{Hb}$, serum ferritin and TSAT at diagnosis of anaemia were similar or slightly lower in the follow-up survey, and the percentage of patients presenting with severe anaemia $(\mathrm{Hb}<8 \mathrm{~g} / \mathrm{dL})$ was higher $(25$ vs. $15 \%)$. Slightly more evaluable CIA patients were iron-deficient at diagnosis of anaemia (serum ferritin $\leq 30 \mathrm{ng} / \mathrm{mL}, 27$ vs. $17 \%$; serum ferritin $\leq 100 \mathrm{ng} / \mathrm{mL}, 50$ vs. $36 \%$; TSAT $\leq 20 \%$, 39 vs. $29 \%$ ). Thirty-one percent of patients received iron therapy (vs. $24 \%$ in 2009), and the majority of these received oral iron. Compared to 2009, slightly more iron-treated patients received i.v. iron (40 vs. $33 \%$ ). 
Fig. 2 a Treatments used for CIA. *Patients who received $\mathrm{RBC}$ transfusions at some stage (survey 1) or during the last 12 months (survey 2 ); ${ }^{\dagger}$ current (survey 1) or last (survey 2) treatment. $R B C$ red blood cells, ESA erythropoiesis-stimulating agents. b Administration routes used for iron therapy; ${ }^{\dagger}$ current (survey 1) or last (survey 2) treatment received a
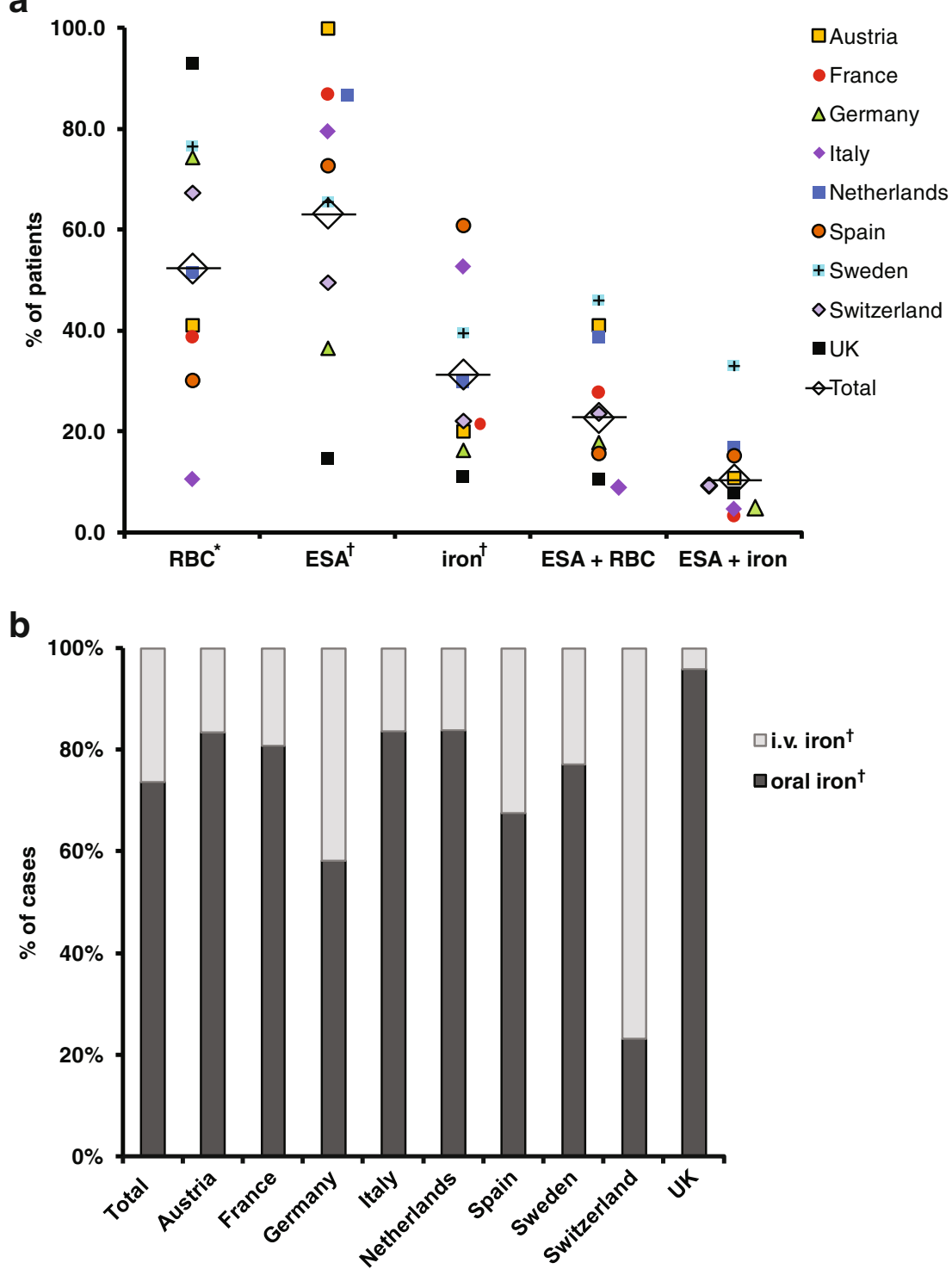

\section{Discussion}

This study on cancer patients treated for CIA revealed substantial variations in routine diagnosis and treatment approaches across Europe. A high proportion of patients had moderate to severe anaemia $(\mathrm{Hb} \leq 10 \mathrm{~g} / \mathrm{dL})$ and a considerable percentage presented with ID (ferritin $\leq 100 \mathrm{ng} / \mathrm{mL}$ or TSAT $\leq 20 \%$ ) at the time of diagnosis of anaemia. The most commonly used anaemia therapy was administration of an ESA but also RBC transfusions were frequently given. About a third of patients received iron supplementation but only a minority of iron-treated patients received i.v. iron, despite clinical evidence for its efficacy [21-26] and recommendations in guidelines to consider its use [5, 14, 15, 17-19].

While current treatment guidelines recommend baseline and periodic assessment of iron status [5, 16, 20], at least a third of patients in this study had no iron status assessed at diagnosis of anaemia. If assessed, diagnosis was mainly based on serum ferritin measurements whereas TSAT was underused as a diagnostic marker. Ferritin is an acute phase protein and often does not accurately reflect iron stores in cancer patients. Although TSAT is to some extend also affected by inflammatory cytokines, it is accepted as a relevant marker of ID and a TSAT value $<20 \%$ is a feature of both absolute and functional ID [5].

The survey data demonstrate that the management of ID in patients with CIA continues to rely on oral iron preparations. Also in the subgroup of ESA-treated patients, concomitant iron supplementation consisted mainly of oral iron. Although oral iron may be used in cancer patients with absolute ID who do not receive any ESA and do not have active inflammation [14], several randomised trials showed superiority of i.v. iron over 
Table. 2 Anaemia treatment practice change over time in survey 1 countries

\begin{tabular}{|c|c|c|}
\hline & $\begin{array}{l}2009 \\
N=1,209\end{array}$ & $\begin{array}{l}2011 \\
N=710\end{array}$ \\
\hline \multicolumn{3}{|l|}{ Used diagnostic tests $(\%)^{\mathrm{a}}$} \\
\hline $\mathrm{Hb}$ & 89 [85-95] & $98[96-100]$ \\
\hline Ferritin & $48[32-56]$ & $49[37-58]$ \\
\hline TSAT & $13[4-23]$ & $23[14-39]$ \\
\hline \multicolumn{3}{|c|}{$\mathrm{Hb}$ and iron status at initial diagnosis of anaemia } \\
\hline Median $\mathrm{Hb}(\mathrm{g} / \mathrm{dL})$ & $9.0[8.9-9.6]$ & $8.8[8.1-9.2]$ \\
\hline Median ferritin (ng/mL) & $165[100-237]$ & $100[45-121]$ \\
\hline Median TSAT (\%) & $28[18-30]$ & $25[15-34]$ \\
\hline \multicolumn{3}{|l|}{$\%$ below cut-offs ${ }^{\mathrm{b}}$} \\
\hline $\mathrm{Hb} \leq 10 \mathrm{~g} / \mathrm{dL}$ & $72[61-82]$ & $86[76-90]$ \\
\hline $\mathrm{Hb}<8 \mathrm{~g} / \mathrm{dL}$ & $15[9-22]$ & $25[18-36]$ \\
\hline Ferritin $\leq 100 \mathrm{ng} / \mathrm{mL}$ & $36[21-49]$ & $50[31-74]$ \\
\hline Ferritin $\leq 30 \mathrm{ng} / \mathrm{mL}$ & $17[8-21]$ & $27[13-43]$ \\
\hline $\mathrm{TSAT} \leq 20 \%$ & $29[18-60]$ & 39 [15-63] \\
\hline \multicolumn{3}{|l|}{ Used treatment options $(\%)^{\mathrm{c}}$} \\
\hline $\begin{array}{l}\text { Iron therapy } \\
\text { Among iron-treated patients }\end{array}$ & $24[9-55]$ & $31[20-49]$ \\
\hline - Iron monotherapy & $23[10-40]$ & $30[10-59]$ \\
\hline- Iron + ESA and/or RBC & $77[60-90]$ & $70[44-90]$ \\
\hline - Oral iron & 67 [22-100] & $60[8-87]$ \\
\hline - i.v. iron & $33[0-78]$ & 40 [13-92] \\
\hline ESA & $47[13-81]$ & $45[19-88]$ \\
\hline $\mathrm{RBC}$ & $54[27-80]$ & $56[32-83]$ \\
\hline $\mathrm{ESA}+\mathrm{RBC}$ & $15[4-26]$ & $12[5-19]$ \\
\hline
\end{tabular}

Data shown for all countries combined and range across countries; $\mathrm{Hb}$ haemoglobin, TSAT transferrin saturation, ESA erythropoiesis-stimulating agent, $R B C$ red blood cell

a $\%$ of all patients

$\mathrm{b}_{\%}$ of tested patients

${ }^{\mathrm{c}} \%$ of treated patients

oral iron in iron-deficient patients scheduled for initial or ongoing ESA-treatment (Table 3) [14, 15, 17-19]. Intravenous iron supplementation resulted in increased haematological response, reduced need for transfusions and faster correction of anaemia [21-28]. In contrast, oral iron did not improve response vs. no iron in ESA-treated cancer patients [21,25]. Side effects were similar in study treatment groups, confirming that only very few clinically relevant adverse events are observed with the new formulations of i.v. iron [29, 30]. Good tolerability of i.v. iron has been shown not only in cancer patients [5] but also in other patient populations with chronic conditions, such as chronic heart failure (FAIR-HF) [31] or chronic kidney disease [32]. Since cancer patients frequently present with multiple comorbidities and cancer therapies are often cardioand/or nephrotoxic, these are important considerations [33].

Interestingly, $22 \%$ of iron-treated patients in this study received iron as monotherapy (5\% i.v.; $17 \%$ oral). Data from
Table. 3 Randomised controlled trials on i.v. iron compared to oral or no iron supplementation of ESAs in cancer patients

\begin{tabular}{lll}
\hline Study & Treatment arm & Response rate ${ }^{\mathrm{a}}$ (\%) \\
\hline Auerbach 2004 [21] & i.v. iron & $68^{*}$ \\
& oral iron & 36 \\
& no iron & 25 \\
Hedenus 2007 [24] & i.v. iron & $87^{*}$ \\
& no iron & 53 \\
Henry 2007 [25] & i.v. iron & $53^{*}$ \\
& oral iron & 36 \\
Bastit 2008 [23] & no iron & 36 \\
Pedrazzoli 2008 [26] & i.v. iron & $86^{*}$ \\
& standard & 73 \\
Auerbach 2010 [22] & i.v. iron & $77^{*}$ \\
& no iron & 62 \\
Steensma 2011 [33, 34] & i.v. iron & $82^{*}$ \\
& no iron & 63 \\
& i.v. iron & $70(80 \%)^{\mathrm{b}}$ \\
& oral iron & 67 \\
Beguin 2013 [28] & no iron & 65 \\
& i.v. iron & $100^{*}$ \\
& no iron & 79 \\
\hline
\end{tabular}

${ }^{*} p<0.05$ vs. no iron (and oral iron if tested); response rates for oral iron were not significantly different vs. no iron in any of the studies with an oral iron treatment arm

${ }^{\mathrm{a}}$ Response was defined as either $\mathrm{Hb}$ increase $\geq 2 \mathrm{~g} / \mathrm{dL}, \mathrm{Hb} \geq 11 \mathrm{~g} / \mathrm{dL}, \mathrm{Hb}$ $\geq 12 \mathrm{~g} / \mathrm{dL}$ or $\mathrm{Hb} \geq 13 \mathrm{~g} / \mathrm{dL}$ in the different studies

${ }^{\mathrm{b}}$ Patients who received at least $750 \mathrm{mg}$ iron [34]

a recently published large prospective observational study indicate that i.v. iron as sole therapy of anaemia in cancer can increase $\mathrm{Hb}$ levels even without concomitant ESA [35]. This data is supported by the results of four smaller randomised studies [36-39], yet further studies are warranted.

More than half of all patients in this study received RBC transfusions. Further inquiries revealed that transfusions were given on a regular basis, and not only as rescue therapy, possibly reflecting suboptimal results obtained with ESA alone or in combination with oral iron. The frequent use of transfusions in patients with CIA is surprising, considering the health risks associated with this treatment. Possible complications of RBC transfusions include transfusion reactions, alloimmunisation, transfusion-related acute lung injury (TRALI), transfusionassociated circulatory overload (TACO), increased risk of infections, thromboembolic complications and transfusiontransmitted infections $[12,40]$. Although safety measures have reduced the incidence of transfusion-transmitted HIV, $\mathrm{HCV}$ and HBV infections, newly emerging and several re-emerging pathogens that are currently not tested for remain a risk [41]. In many studies, an adverse clinical outcome (higher local tumour recurrence rate or shorter survival time) has been shown for cancer 
patients receiving transfusions [13]. In addition, there are several procedural problems associated with RBCs (e.g. transfusion of $\mathrm{RBC}$ to $\mathrm{ABO}$-incompatible recipients, availability of sufficient blood donations and quality issues). Guidelines therefore recommend preventing RBC transfusions by timely recognition and appropriate treatment of anaemia [14-16].

Findings strikingly similar to this study's were reported in a retrospective observational study in France $(N=276)$ and a recent cross-sectional survey in Germany $(N=3,867)[42,43]$. Both studies showed frequent use of RBC transfusions in anaemic cancer patients and disregard of available treatment options for iron deficiency. Among iron-treated patients, iron therapy mainly consisted of oral iron. The authors concluded that routine treatment practice did not reflect current guidelines which recommend prevention of RBC transfusions and the i.v. route for iron supplementation, based on evidence that oral iron is ineffective in cancer-associated anaemia [21, 25].

Our follow-up survey, 2 years after the first one, revealed only minor changes in management practices. Notably, there was an increase in the use of TSAT as a diagnostic marker. In addition, in year 2011, $\mathrm{Hb}$ levels at diagnosis of anaemia were slightly lower, possibly reflecting a general reservation regarding the use of ESA as a consequence of discussions about its safety [11]. However, a 2-year interval may not be long enough for significant changes in management practices.

The majority of patients in this study population had already reached a moderate or severe stage of anaemia at the time of anaemia diagnosis. A possible reason for this may be that diagnostic tests and treatment were only initiated when anaemia symptoms were noticed.

Some caution is required in generalising the results of this study. The study was designed to capture diagnosis and treatment of CIA in routine practice in cancer patients who have already been treated for CIA. Among those, analysis was limited to the last five patients treated by each participating physician. Only limited information such as the presence of comorbidities was obtained, but no detailed data on the clinical history and the specific cause(s) of anaemia were collected. While the majority of cancer patients undergoing chemotherapy become anaemic, the cause of anaemia often is multifactorial and treatment decisions should be based on its underlying aetiology. Therefore, iron status should carefully be assessed, in addition to haemoglobin levels, when use of iron replacement therapy is considered in CIA patients. The significant variability in anaemia management observed in this study may not only reflect differences in appraisal of treatment benefits and insufficient concordance with treatment recommendations but also country-specific differences in reimbursement policies. The low utilisation of ESAs in the UK for instance may mainly be due to guidance against ESA use by the National Institute of Clinical Excellence (NICE).

Although some statistically significant differences in the use of diagnostic tests and anaemia treatment options were observed between entirely hospital-based and at least partially office-based medical oncologists and/or haematologists, these were of small magnitude, particularly in comparison to intercountry differences. The wide variation in diagnostic approaches seen between the countries is one of the main findings of this study, indicating the heterogeneity of patient management across Europe, and probably also between centres/practices within individual countries.

\section{Conclusions}

This study shows considerable variations in the diagnosis and therapy of CIA across different European countries. TSAT, a simple parameter indicating insufficient iron supply, was used only rarely, while ferritin levels were more frequently obtained although this parameter is a less reliable marker for iron status in patients with inflammatory conditions such as cancer. ID was mainly treated with oral iron while i.v. iron was rarely used. Information about the i.v. option, that has been shown to significantly increase the response to ESAs when given concomitantly, should be better promoted. More efficient strategies should be developed to minimise the use of blood transfusions and to optimise anaemia management in patients with cancer. Developing practical tools such as simplified treatment algorithms may be helpful in clinical management of anaemia and iron deficiency.

Acknowledgments Preparation and conduct of the study have been sponsored by Vifor Pharma, Switzerland. The first and second surveys were conducted by A+A Healthcare Market Research, UK. The followup survey was conducted by EUMARA AG, Germany. Medical writing support in the preparation of the manuscript was provided by Bettina Dümmler, SFL Regulatory Affairs \& Scientific Communication, Switzerland and funded by Vifor Pharma.

Conflict of interest All authors served as members of an advisory board of Vifor Pharma. HL has received consulting fees and speaker honoraria from Vifor Pharma. MA has received consulting fees and/or speaker honoraria and/or study grants from Vifor Pharma, Sandoz, Amgen, Roche, Hexal and Hospira. CB has received speaker honoraria from Jansen Cilag, Roche and consulting fees from Hexal. The university that employs JG receives payments to support clinical trials underway from Amgen. $\mathrm{MH}$ has received consulting fees and/or speaker honoraria from Vifor Pharma, Pharmacosmos AS and Takeda. TJL has not received any honoraria from any company within the last 3 years. Prior to that TJL received honoraria from Janssen, Vifor Pharma, Amgen and Roche. AÖ has received honoraria for advisory board meetings and conduct of clinical trials of Vifor Pharma. BR and DM are employees of Vifor Pharma. YB has received consulting fees and speaker honoraria from Vifor Pharma. The authors are fully responsible for content and editorial decisions for this paper. All authors had access to the primary study data. All authors reviewed the paper and approved the final version.

Open Access This article is distributed under the terms of the Creative Commons Attribution Noncommercial License which permits any noncommercial use, distribution, and reproduction in any medium, provided the original author(s) and the source are credited. 


\section{References}

1. Ludwig H, Van BS, Barrett-Lee P, Birgegard G, Bokemeyer C, Gascon P, Kosmidis P et al (2004) The European Cancer Anaemia Survey (ECAS): a large, multinational, prospective survey defining the prevalence, incidence, and treatment of anaemia in cancer patients. Eur J Cancer 40:2293-2306

2. Ludwig H, Muldur E, Endler G, Hubl W (2013) Prevalence of iron deficiency across different tumors and its association with poor performance status, disease status and anemia. Ann Oncol 24: 1886-1892

3. Crawford J, Cella D, Cleeland CS, Cremieux PY, Demetri GD, Sarokhan BJ, Slavin MB et al (2002) Relationship between changes in hemoglobin level and quality of life during chemotherapy in anemic cancer patients receiving epoetin alfa therapy. Cancer 95 : 888-895

4. Grotto HZ (2008) Anaemia of cancer: an overview of mechanisms involved in its pathogenesis. Med Oncol 25:12-21

5. Aapro M, Osterborg A, Gascon P, Ludwig H, Beguin Y (2012) Prevalence and management of cancer-related anaemia, iron deficiency and the specific role of intravenous iron. Ann Oncol 23:1954-1962

6. Beguin Y (2002) Prediction of response and other improvements on the limitations of recombinant human erythropoietin therapy in anemic cancer patients. Haematologica 87:1209-1221

7. Thomas DW, Hinchliffe RF, Briggs C, Macdougall IC, Littlewood T, Cavill I (2013) Guideline for the laboratory diagnosis of functional iron deficiency. Br J Haematol 161:639-648

8. Gabrilove JL, Cleeland CS, Livingston RB, Sarokhan B, Winer E, Einhorn LH (2001) Clinical evaluation of once-weekly dosing of epoetin alfa in chemotherapy patients: improvements in hemoglobin and quality of life are similar to three-times-weekly dosing. J Clin Oncol 19:2875-2882

9. Littlewood TJ, Bajetta E, Nortier JW, Vercammen E, Rapoport B (2001) Effects of epoetin alfa on hematologic parameters and quality of life in cancer patients receiving nonplatinum chemotherapy: results of a randomized, double-blind, placebo-controlled trial. J Clin Oncol 19:2865-2874

10. Ludwig H, Aapro M, Bokemeyer C, MacDonald K, Soubeyran P, Turner M, Albrecht T et al (2009) Treatment patterns and outcomes in the management of anaemia in cancer patients in Europe: findings from the Anaemia Cancer Treatment (ACT) study. Eur J Cancer 45: $1603-1615$

11. Bohlius J, Schmidlin K, Brillant C, Schwarzer G, Trelle S, Seidenfeld J, Zwahlen M et al. (2009) Erythropoietin or darbepoetin for patients with cancer-meta-analysis based on individual patient data. Cochrane Database Syst Rev:CD007303

12. Spahn DR, Moch H, Hofmann A, Isbister JP (2008) Patient blood management: the pragmatic solution for the problems with blood transfusions. Anesthesiology 109:951-953

13. Khorana AA, Francis CW, Blumberg N, Culakova E, Refaai MA, Lyman GH (2008) Blood transfusions, thrombosis, and mortality in hospitalized patients with cancer. Arch Intern Med 168:2377-2381

14. National Comprehensive Cancer Network Inc (2014) NCCN practice guidelines in oncology: cancer and chemotherapy-induced anemia v.2. http://www.nccn.org/professionals/physician_gls/f_guidelines. asp\#supportive (28 August 2013, date last accessed).

15. Bokemeyer C, Aapro MS, Courdi A, Foubert J, Link H, Osterborg A, Repetto L et al (2007) EORTC guidelines for the use of erythropoietic proteins in anaemic patients with cancer: 2006 update. Eur J Cancer $43: 258-270$

16. Rizzo JD, Brouwers M, Hurley P, Seidenfeld J, Arcasoy MO, Spivak JL, Bennett CL et al (2010) American Society of Hematology/American Society of Clinical Oncology clinical practice guideline update on the use of epoetin and darbepoetin in adult patients with cancer. Blood 116: 4045-4059
17. Aapro MS, Link H (2008) September 2007 update on EORTC guidelines and anemia management with erythropoiesis-stimulating agents. Oncologist 13(Suppl 3):33-36

18. Mikhael J, Melosky B, Cripps C, Rayson D, Kouroukis CT (2007) Canadian supportive care recommendations for the management of anemia in patients with cancer. Curr Oncol 14:209-217

19. Dirix L, Awada D, Bron D, Canon JL, De Grève J, Humblet Y, Peeters $M$ et al (2010) Practice guidelines on the use of erythropoiesis-stimulating agents in the treatment of chemotherapyinduced anemia. Belg J Med Oncol 4:57-64

20. Schrijvers D, De SH, Roila F (2010) Erythropoiesis-stimulating agents in the treatment of anaemia in cancer patients: ESMO Clinical Practice Guidelines for use. Ann Oncol 21(Suppl 5):v244-v247

21. Auerbach M, Ballard H, Trout JR, Mcllwain M, Ackerman A, Bahrain H, Balan S et al (2004) Intravenous iron optimizes the response to recombinant human erythropoietin in cancer patients with chemotherapy-related anemia: a multicenter, open-label, randomized trial. J Clin Oncol 22:1301-1307

22. Auerbach M, Silberstein PT, Webb RT, Averyanova S, Ciuleanu TE, Shao J, Bridges K (2010) Darbepoetin alfa 300 or 500 ug once every 3 weeks with or without intravenous iron in patients with chemotherapy-induced anemia. Am J Hematol 85:655-663

23. Bastit L, Vandebroek A, Altintas S, Gaede B, Pinter T, Suto TS, Mossman TW et al (2008) Randomized, multicenter, controlled trial comparing the efficacy and safety of darbepoetin alpha administered every 3 weeks with or without intravenous iron in patients with chemotherapy-induced anemia. J Clin Oncol 26:1611-1618

24. Hedenus M, Birgegard G, Nasman P, Ahlberg L, Karlsson T, Lauri B, Lundin $\mathrm{J}$ et al (2007) Addition of intravenous iron to epoetin beta increases hemoglobin response and decreases epoetin dose requirement in anemic patients with lymphoproliferative malignancies: a randomized multicenter study. Leukemia 21:627-632

25. Henry DH, Dahl NV, Auerbach M, Tchekmedyian S, Laufman LR (2007) Intravenous ferric gluconate significantly improves response to epoetin alfa versus oral iron or no iron in anemic patients with cancer receiving chemotherapy. Oncologist 12:231-242

26. Pedrazzoli P, Farris A, Del PS, Del GF, Ferrari D, Bianchessi C, Colucci $\mathrm{G}$ et al (2008) Randomized trial of intravenous iron supplementation in patients with chemotherapy-related anemia without iron deficiency treated with darbepoetin alpha. J Clin Oncol 26:1619-1625

27. Gafter-Gvili A, Rozen-Zvi B, Vidal L, Leibovici L, Vansteenkiste J, Gafter U, Shpilberg O (2013) Intravenous iron supplementation for the treatment of chemotherapy-induced anaemia - systematic review and meta-analysis of randomised controlled trials. Acta Oncol 52:18-29

28. Beguin Y, Maertens J, De PB, Schots R, Seidel L, Bonnet C, Hafraoui $\mathrm{K}$ et al. (2013) Darbepoetin-alfa and intravenous iron administration after autologous hematopoietic stem cell transplantation: a prospective multicenter randomized trial. Am J Hematol

29. Bailie GR, Horl WH, Verhof JJ (2011) Differences in spontaneously reported hypersensitivity and serious adverse events for intravenous iron preparations: comparison of Europe and North America. Drug Res 61:267-275

30. Geisser P (2009) The pharmacology and safety profile of ferric carboxymaltose (Ferinject ${ }^{(B)}$ ): structure/reactivity relationships of iron preparations. Port J Nephrol Hypert 23:11-16

31. Anker SD, Comin CJ, Filippatos G, Willenheimer R, Dickstein K, Drexler H, Luscher TF et al (2009) Ferric carboxymaltose in patients with heart failure and iron deficiency. N Engl J Med 361:2436-2448

32. Kidney disease: Improving global outcomes (KDIGO) anemia work group (2012) KDIGO clinical practice guideline for anemia in chronic kidney disease. Kidney inter, Suppl 2:279-335

33. Steensma DP, Sloan JA, Dakhil SR, Dalton R, Kahanic SP, Prager DJ, Stella PJ et al (2011) Phase III, randomized study of the effects of parenteral iron, oral iron, or no iron supplementation on the erythropoietic response to darbepoetin alfa for patients with chemotherapyassociated anemia. J Clin Oncol 29:97-105 
34. Steensma DP, Sloan JA, Loprinzi CL (2011) Reply to M. Aapro et al J Clin Oncol 29:e527-e528

35. Steinmetz T, Tschechne B, Harlin O, Klement B, Franzem M, Wamhoff J, Tesch H et al (2013) Clinical experience with ferric carboxymaltose in the treatment of cancer- and chemotherapyassociated anaemia. Ann Oncol 24:475-482

36. Kim YT, Kim SW, Yoon BS, Cho HJ, Nahm EJ, Kim SH, $\mathrm{Kim} \mathrm{JH}$ et al (2007) Effect of intravenously administered iron sucrose on the prevention of anemia in the cervical cancer patients treated with concurrent chemoradiotherapy. Gynecol Oncol 105:199-204

37. Dangsuwan P, Manchana T (2010) Blood transfusion reduction with intravenous iron in gynecologic cancer patients receiving chemotherapy. Gynecol Oncol 116:522-525

38. Athibovonsuk P, Manchana T, Sirisabya N (2013) Prevention of blood transfusion with intravenous iron in gynecologic cancer patients receiving platinum-based chemotherapy. Gynecol Oncol 131: $679-682$
39. Hedenus M, Karlsson T, Ludwig H, Felder M, Roubert B, Birgegard G (2013) Intravenous ferric carboxymaltose as sole anemia therapy in patients with lymphoid malignancies, chemotherapy-induced anemia and functional iron deficiency. ASH Annual Meeting Abstracts. 3439 (poster)

40. Schrijvers D (2011) Management of anemia in cancer patients: transfusions. Oncologist 16(Suppl 3):12-18

41. Hofmann A, Farmer S, Shander A (2011) Five drivers shifting the paradigm from product-focused transfusion practice to patient blood management. Oncologist 16(Suppl 3):3-11

42. Spielmann M, Luporsi E, Ray Coquard I, De BS, Azria D, Lasocki S, Lafuma A et al (2012) Diagnosis and management of anaemia and iron deficiency in patients with haematological malignancies or solid tumours in France in 2009-2010: the AnemOnHe study. Eur J Cancer 48:101-107

43. Link H, Schmitz S (2013) Treatment of cancer-associated anaemia: results from a two-day cross-sectional survey in Germany. Onkologie $36: 266-272$ 